\title{
Development of the Gall Bladder, and Caudate and Quadrate Lobes of the Liver: A Fetal Morphometric Study
}

\author{
MAMATHA HOSAPATNA, ANNE D SOUZA AND VRINDA HARI ANKOLEKAR \\ Department of Anatomy, Kasturba Medical College, Manipal Academy of Higher Education, Manipal, 576104 India \\ Received 22 December 2017, accepted 23 April 2018 \\ J-STAGE advance publication 19 November 2018 \\ Edited by TAKUJI TORIMURA
}

\begin{abstract}
Summary: Introduction: The gall bladder (GB) is a storage reservoir that allows bile acids to be delivered in a high concentration. The quadrate (QL) and caudate lobes (CL) are functional parts of the liver. The knowledge of the gross and developmental anatomy of GB and CL and QL of liver is important for surgeons who operate in this region. The present study was conducted to examine the developmental sequence and morphometry of the GB, and $\mathrm{CL}$ and QL of liver.

Materials and Methods: In the present cross sectional study the parameters measured were length of GB from the neck to the lowest point on the fundus, and the length and width of QL and CL measured at the midpoint. The data was analyzed statistically and the various parameters were correlated using Pearson's correlation.

Results: There was a statistically significant correlation indicating that the growth of GB, QL and CL was proportional to the gestational age (GA). The variations in the morphology of the GB were also noted. In two specimens it was found that the GB was embedded partially in the substance of the liver and failed to reach the inferior border of the liver.
\end{abstract}

Conclusion: The regression equations calculated in the study provide a tool to estimate the lengths of GB, QL and CL prenatally.

Key words gall bladder, caudate lobe, quadrate lobe, developmental anatomy, porta hepatis

\section{INTRODUCTION}

The gall bladder (GB) lies on the undersurface of the right lobe of the liver [1,2]. It is a pear-shaped distensible structure consisting of a fundus, body and neck. The GB receives its blood supply from the cystic artery, which is a branch from the right hepatic artery $[3,4]$.

The quadrate lobe (QL) and caudate lobe (CL) are functional parts of the right lobe of the liver [2]. The caudate lobe, also known as the posterior hepatic segment, is situated between the ligamentum venosum, the porta and the fossa for the inferior vena cava. It is supplied by both the right and left branches of the portal vein [2]. Occlusion of hepatic venous outflow may lead to Budd-Chiari syndrome, resulting in hypertrophy of the CL [5]. The quadrate lobe of the liver is bounded by the fossa for gall bladder, fissure for the ligamentum teres, porta hepatis and caudate process and the inferior border of liver [6].

Embryologically, the liver develops from a hepatic bud that arises from endoderm in the region of the junction of the foregut and yolk sac at the fourteensomite stage. The hepatic bud grows within the mesogastrium, reaches the septum transversum and divides into right and left branches. Each branch gives rise to clusters of liver cells forming two solid masses which later give rise to the right and left lobes of liver [6]. Anomalies related to excessive development of the liver may lead to the formation of accessory lobes, which may carry the risk of torsion [3].

Corresponding Author: Dr. Vrinda Hari Ankolekar, Department of Anatomy, Kasturba Medical College, Manipal Academy of Higher Education, Manipal 576104, Karnataka, India. E-mail:vrinda.hari@manipal.edu 
Knowledge of the gross and developmental anatomy of the GB, and CL and QL of liver is growing in importance as congenital and acquired diseases of the GB are increasing. The present study was conducted to determine the length, width and variations of the GB, and CL and QL of liver, during antenatal development.

\section{MATERIALS AND METHODS}

The present study was conducted at the Department of Anatomy, Kasturba Medical College, Manipal using 18 formalin fixed fetuses with gestational age (GA) ranging from 12 to 36 weeks without any congenital anomaly. The study was carried out for a period of 6 months. The fetuses were collected from the Department of Obstetrics and Gynecology, Kasturba Hospital. Crown rump length (CRL) of the fetuses was measured between the vertex of the scalp and the midpoint of apices of the buttocks. The liver and gallbladder were removed. Livers and gallbladders with visible congenital malformations were excluded from the study. The study was approved by the Institutional Ethics Committee (IEC) of Kasturba Medical College, Manipal, India. The following parameters were measured using digital calipers.

1. Length of GB was measured from the neck to the lowest point on the fundus

2. Length and width of QL, measured from its midpoint

3. Length and width of CL, measured from its midpoint

The parameters measured are shown in Figs A-1, $1 \mathrm{a}$ and $1 \mathrm{~b}$.
The data was analyzed statistically using SPSS version 16 and the various parameters were correlated using Pearson's correlation.

\section{RESULTS}

The GA of the fetuses included in the study ranged from 12 to 36 weeks. The CRL ranged from $16.5 \mathrm{~cm}$ to $35.5 \mathrm{~cm}$. The descriptive statistics of the measured parameters are shown in Table 1. The sample was assessed using Kolmogorov Smirnov's test for the normality of distribution and Levene's test for the homogeneity of variance. As the sample showed a normal distribution, parametric tests were used for the further statistical analysis.

Pearson's correlation was applied to assess the correlation of the parameters measured with GA and CRL (Table 2). There was a statistical significant correlation indicating that the growth of $\mathrm{GB}, \mathrm{QL}$ and $\mathrm{CL}$ was proportional to the GA.

As there was a statistically significant correlation between the GA and the measured parameters, linear regression was used to construct the regression equations. GB length, QL length, and QL width could be calculated in $\mathrm{mm}$ as follows. Regression equations were calculated for the 18 specimens included in the study.

Length of $\mathrm{GB}=0.36 \times \mathrm{GA}+10.1$

Length of $\mathrm{QL}=0.66 \times \mathrm{GA}+6.13$

Width of $\mathrm{QL}=0.2 \times \mathrm{GA}+6.37$

Variations in the morphology of the GB were also noted. At term the GB was fully grown and the fundus was at the level of the inferior border of the liver. In two specimens it was found that the GB was embed-
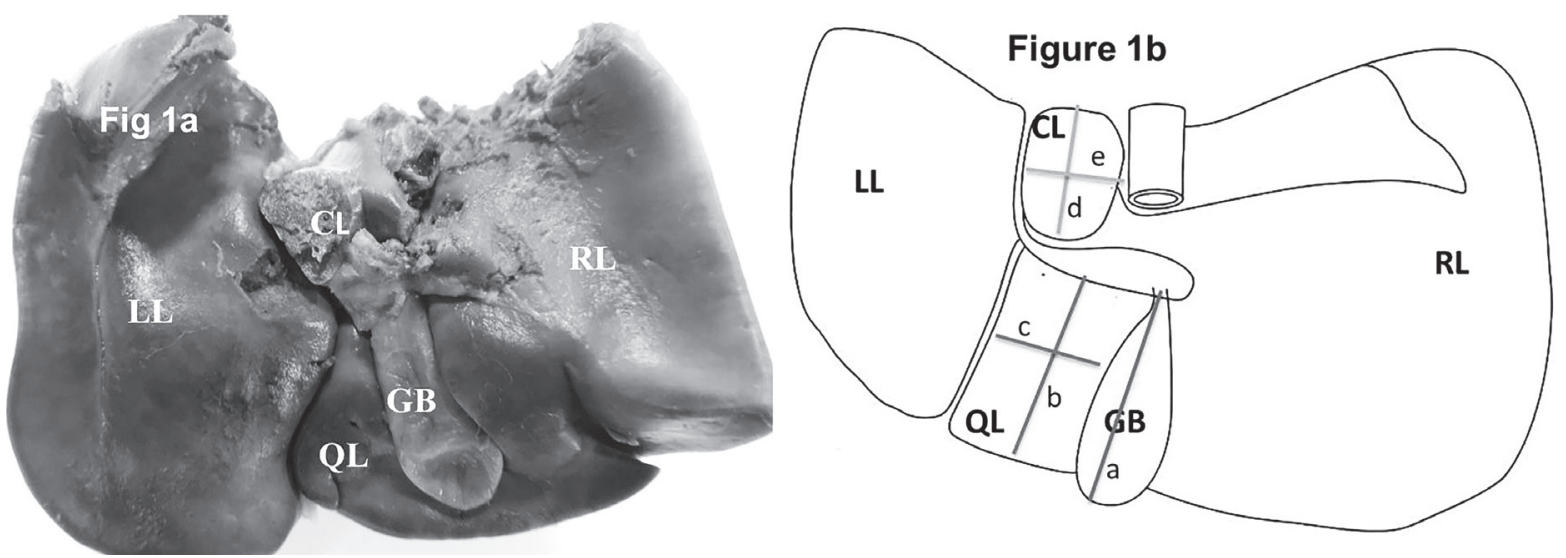

Fig. 1. Term fetal liver (1a) and its schematic representation (1b) showing the various parameters measured. LL- left lobe, RL- right lobe, QL- quadrate lobe, CL- caudate lobe, a- length of GB, b- length of QL, c- breadth of QL

a- Length of GB b- Length of QL c- Width of QL d- Length of CL e- Width of CL 
TABLE 1.

Descriptive statistics of the measured parameters

\begin{tabular}{lccc}
\hline Parameter measured & Minimum $(\mathrm{mm})$ & Maximum $(\mathrm{mm})$ & Mean and SD $(\mathrm{mm})$ \\
$\mathrm{N}=18$ & 12 & 29 & $18.6 \pm 4.4$ \\
Length of GB & 16 & 38 & $21.5 \pm 5.5$ \\
Length of QL & 8 & 21 & $11.1 \pm 3.5$ \\
Width of QL & 9 & 27 & $15.6 \pm 5.3$ \\
Length of CL & 7 & 16 & $10.2 \pm 2.6$ \\
Width of CL & & & \\
\hline
\end{tabular}

TABLE 2.

The Pearson's correlation coefficients $(r)$ and $p$ values show statistically significant correlation for all the measured parameters.

\begin{tabular}{lcr}
\hline Parameters correlated & r value & p value \\
\hline GA and length of GB & 0.5 & 0.001 \\
GA and length of QL & 0.8 & $<0.001$ \\
GA and width of QL & 0.4 & 0.03 \\
CRL and length of GB & 0.6 & $<0.001$ \\
CRL and length of QL & 0.9 & $<0.001$ \\
CRL and width of QL & 0.5 & 0.008 \\
\hline
\end{tabular}

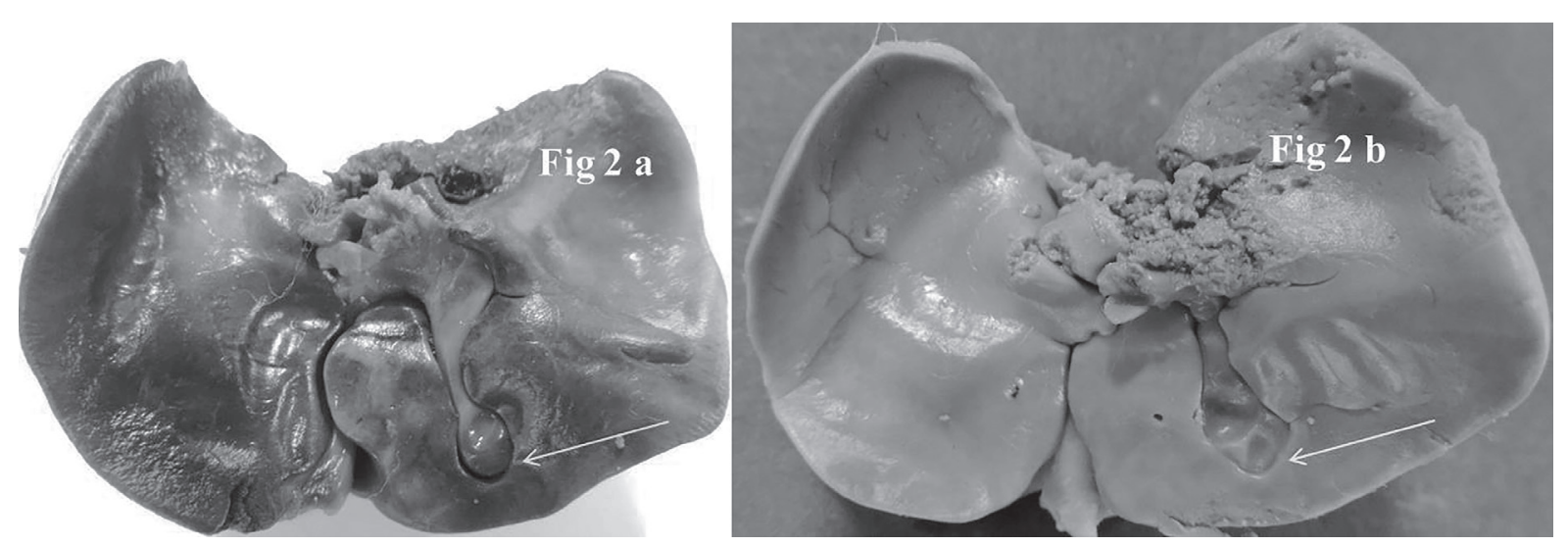

Fig. 2. In a term fetus, GB embedded partially within the substance of liver and the fundus fails to reach the inferior border of the liver (arrow).

ded partially in the substance of the liver and failed to reach the inferior border of the liver at term (Fig $2 \mathrm{a}$ and $2 b$ ).

\section{DISCUSSION}

The fetal GB seen during antenatal sonography presents as an anechoic, elliptical structure to the right of the intrahepatic umbilical vein. As gestation advances, the gall bladder grows in a predictable fashion $[11,12]$. A large gall bladder would be a postnatal feature of trisomy [13]. Therefore size evaluation of the fetal gall bladder may be an indicator of the risk of chromosomal aneuploidy [13].

In a fetal study by Sangeetha et al the CRL ranged from 51-338 mm. The range for GA was 70-262 days. The range for GB length was 11.1-33.5 $\mathrm{mm}$. The mean value of GB length was $17.630 \pm 6.5412 \mathrm{~mm}$ [14]. 
In the present study the average length of GB was $18.6 \pm 4.4 \mathrm{~mm}$, which was similar to the previous results.

Some authors have observed that the fetal GB can be visualised from early in the second trimester; hence non-visualization of the fetal GB from this point may indicate cystic fibrosis, gall bladder atresia, and biliary atresia $[15,16]$.

In a study done by Albay et al., the lengths of CL observed in the three trimesters were $5 \pm 1,10 \pm 3,16 \pm$ 3 and $18 \pm 4 \mathrm{~mm}$. CL widths were $4 \pm 1,7 \pm 2,11 \pm 2$ and $13 \pm 3 \mathrm{~mm}$. QL lengths were $8 \pm 1.14 \pm 4,23 \pm 6$ and $29 \pm 5 \mathrm{~mm}$. QL widths were $4 \pm 1,8 \pm 3,13 \pm 4$ and $17 \pm$ $5 \mathrm{~mm}$ in the first, second, third and full term respectively. He demonstrated a high positive correlation between the sizes of the CL and the QL, and GA. Comparisons of these parameters among groups revealed no significant difference in the height of the CL between the 3rd and 4th groups, while the widths of the caudate and QL as well as the lengths of the QL demonstrated a significant increase $(p<0.05)$. There were no differences in the parameters between males and females. There was a statistically significant relationship between the size of gallbladder and the GA [17].

Murao et al. found a high correlation between liver size and other parameters between the 19th week and term, and concluded that liver size could be used to assess fetal growth [18]. Roberts et al studied the importance of diagnosis and follow-up of gestational diabetes and hepatomegaly and observed that the length of the fetal liver was $12 \%$ greater in diabetic pregnancies at 18 weeks when compared to the non-diabetic pregnancies. [19].

The possibility of abnormal liver has to be kept in mind when an abdominal mass is encountered. In the present study, the variations in the morphology of the GB were also noted. In two specimens it was found that the GB was embedded partially in the substance of the liver and failed to reach its lower border.

In a study by Aktan et al., the left lobe was absent in one case and the caudate lobe was absent in 4 cases [20]. The knowledge of liver anomalies, especially of the CL and QL of liver is important to achieve a correct preoperative diagnosis, and because it will help the surgeon in planning biliary surgery or a portosystemic anastomosis. Many studies suggest that fetal liver size measurements are valuable tools in detecting intrauterine growth retardation, gestational diabetes, intrauterine infections, isoimmunization, fetal heart failure, neoplasms, certain metabolic diseases and fetal macrosomias and their follow-up [21-23].

A thorough knowledge of the anatomy of the fetal liver and gall bladder is essential for the diagnosis and treatment of various disorders, and this study will be helpful to surgeons who work in this region. In the present study, the parameters were not compared between male and female fetuses as there were only two female fetuses were available. The regression equation was not calculated for the parameters of CL as the authors were unable to measure the parameters in all the specimens due to tissue damage.

As several studies about the morphology of the fetal liver are available in the literature, the current study concentrated only on the CL and QL and correlated them with the GA.

\section{CONCLUSION}

The regression equations calculated in this study provide a tool for estimating the lengths of GB, QL and CL prenatally. The findings in this study would be useful for ultrasound investigations of the liver and furthermore, the data will be helpful in the evaluation of fetal autopsy material.

\section{REFERENCES}

1. Shaffer EA. Control of gall bladder motor function. Aliment Pharmacol Ther. 2000; 14(2):2-8.

2. Standring S. Gray's anatomy, The anatomical basis of clinical practice. In: Borley NR, Healy JC. Abdomen and Pelvis. $40^{\text {th }}$ edn. Spain (Churchil Livingstone Elsevier.): 2008; 1177.

3. Toouli J and Craig A. Sphincter of Oddi- Function and Dysfunction. Can J Gastroenterol. 2000; 14:411-419.

4. Frierson HF. The gross anatomy and histology of the gall bladder, extrahepatic bile duct ducts, vaterian system and minor papilla. Am J Surg Pathol. 1989; 13:146.

5. Sato S, Watanabe M, Nagasawa S, Niigaki M, Sakai S et al. Laparoscopic observations of congenital anomalies of the liver. Gastrointest Endosc. 1998; 47:136-140.

6. Dutta AK (2005). Essentials of Human Embryology. $3^{\text {rd }}$ edn. Calcutta (Current Books International) 142.

7. Sarala HS, Jyothilakshmi TK, and Shubha R. Morphological variations of caudate lobe of the liver and their clinical implications. Int J Anat Res. 2015; 3(2):980-983.

8. Korn MA. Papillary process of the caudate lobe-erroneous sonography interpretation as space occupying lesion. Utraschall Med. 1991; 12(4):197-200.

9. Auh YH, Rosen A, and Rubenstein WA. CT of the papillary process of the caudate lobe of the liver. Am J Roentgenol. $1984 ; 142: 535-538$

10. Daver GB, Bakhshi GD, Patil A, Ellur S, Jain M et al. Bifid liver in a patient with diaphragmatic hernia. Indian J Gastroenterol. 2005; 24(1):27-28.

11. Chan L, Rao BK, Jiang Y, Endicott B, Wapner RJ et al. Fetal gallbladder growth and development during gestation. J Ultrasound Med. 1995; 14:421-425.

12. Goldstein I, Tamir A, Weisman A, Jakobi P, and Copel JA. 
Growth of the fetal gall bladder in normal pregnancies. Ultrasound Obstet Gynecol. 1994; 4:289-293.

13. Jones KL. Chromosomal abnormality syndrome. In: Jones KL, eds. Smith's recognizable patterns of human malformations. $6^{\text {th }}$ ed. Philadelphia: W. B. Sanders Company, 2005.

14. Wazir S and Mahajan A. Prenatal morphometric analysis of human fetal gall bladder. Int J App Basic Med Res. 2013; 3(2): 102-109.

15. Bronshtein M, Weiner Z, Abramovici H, Filmar S, Erlik Y et al. Prenatal diagnosis of gall bladder anomalies - report of 17 cases. Prenat Diagn. 1993; 13:851-861.

16 Duchatel F, Muller F, Oury JF, Mennesson B, Boue J et al. Prenatal diagnosis of cystic fibrosis: ultrasonography of the gallbladder at 17-19 weeks of gestation. Fetal Diagn Ther. $1993 ; 8: 28-36$.

17. Albay S, Malas MA, Koyuncu E, and Evcil EH Morphometry of the gallbladder during the fetal period. Surg Radiol Anat. 2010; 32(4):363-369.

18. Murao F, Takamiya O, Yamamoto $\mathrm{K}$, and Iwanari $\mathrm{O}$. Detection of intrauterine growth retardation based on mea- surements of size of the liver. Gynecol Obstet Invest. 1990; 29:26-31.

19. Roberts AB, Mitchell JM, and Pattison NS. Fetal liver length in normal and isoimmunized pregnancies. Am J Obstet Gynecol. 1989;161:42-46.

20. Aktan ZA, Savas R, Pinar Y, and Arslan O. Lobe and Segment Anomalies Of the Liver, J Anat. Soc. India. 2001; 50(1):15-16.

21. Murao F, Senoh D, Takamiya O, Yamamoto K, Hasegawa $\mathrm{K}$ et al. Ultrasonic evaluation of liver development in the fetus in utero. Gynecol Obstet Invest. 1989; 28:198-201.

22. Murao F, Takamiya O, Yamamoto K, and Iwanari O. Detection of intrauterine growth retardation based on measurements of size of the liver. Gynecol Obstet Invest. 1990; 29:26-31

23. Fleischer AC, Manning FA, Jeanty P, and Romero R. (2000) Sonography Principles of Obstetrics and Gynecology and Clinical Applications. In: Yuksel A, Turkish editor. Ankara, Turkey: 5th ed; p. 109-130, 411-432. 